\title{
Use of Excised Human Skin to Assess the Bioequivalence of Topical Products
}

\author{
T.J. Franz P.A. Lehman S.G. Raney \\ Cetero Research, Fargo, N. Dak., USA
}

\section{Key Words}

Percutaneous absorption • Glucocorticoid

pharmacokinetics $\cdot$ Tretinoin $\cdot$ Bioavailability

Bioequivalence $\cdot$ In vitro:in vivo correlation

\begin{abstract}
Background: Establishing the bioequivalence of topical drug products is a costly and time-consuming process since, with few exceptions, clinical efficacy trials are required. $\mathbf{O} \boldsymbol{b}$ jective: To develop a surrogate for clinical bioequivalence testing through evaluation of the kinetics of drug absorption in vitro through excised human skin. Methods: The percutaneous absorption of seven approved generic topical drug products was compared with their corresponding reference products during preclinical development using the Franz diffusion cell. Thereafter, following the conduct of bioequivalence trials and regulatory approval of these products in the United States, clinical data became available to which the in vitro data were compared. Results: In six of the seven cases the in vitro test:reference ratio for total absorption was close to one and indicated that the products were equivalent, in agreement with the clinical data. Results from the seventh case, in which the test:reference ratio was only 0.63 , indicated that the in vitro model actually had greater sensitivity than the clinical method to detect small differences between products. Conclusion: These data demonstrate the relevance and predictive power of the in vitro human skin model and strongly support its use as a surrogate for in vivo bioequivalence studies.

Copyright $\odot 2009$ S. Karger AG, Basel
\end{abstract}

\section{Introduction}

In vitro:in vivo Correlation: Topical Delivery

Review of the literature of the past $40+$ years reveals the great extent to which our understanding of the fundamentals of percutaneous absorption depends upon a simple, yet multifaceted, model system: the in vitro use of excised animal or human skin mounted as a barrier between two glass chambers. For those who believe that data obtained in vitro using human skin is an adequate representation of living man, the model has become a means to address important issues in clinical pharmacology and toxicology. Is this belief warranted?

Historically, the methods used to evaluate percutaneous absorption in vitro typically segregate into two groups: (a) infinite dose/steady state, in which the skin's outer surface faces a large amount of solvent containing the compound under study, and (b) finite dose/nonsteady state, in which the skin surface faces more physiological conditions and the applied dose is similar to that used in a clinical setting.

Since the infinite dose technique is an inappropriate model in most situations where relevance to living man is desired, Franz set out to validate a finite dose technique that sought to duplicate the conditions most applicable to the use of topical products [1]. The key elements to this approach were: (a) duplicate the essential physical parameters that significantly impact the absorption process (temperature, humidity), and (b) duplicate clinical use conditions as closely as possible (amount of product ap-

\section{KARGER}

Fax +41 613061234 E-Mail karger@karger.ch www.karger.com
(C) 2009 S. Karger AG, Basel

1660-5527/09/0225-0276\$26.00/0

Accessible online at:

www.karger.com/spp
Thomas J. Franz

10716 SE Forest View Lane

Portland, OR 97086 (USA)

Tel. +1 503698 3992, E Mail franzcell@verizon.net 


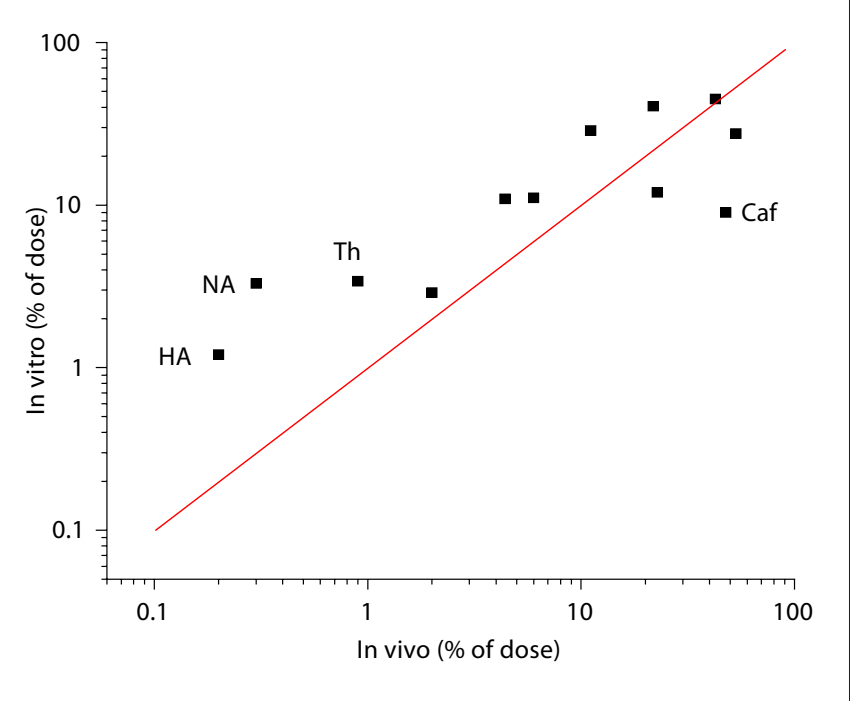

Fig. 1. IVIV comparison of total absorption (\% of applied dose) for twelve organic compounds applied in an acetone vehicle. Line represents theoretical one-to-one correlation. 4- to 10-fold differences between in vitro and in vivo were found for hippuric acid (HA), nicotinic acid (NA), thiourea (Th), and caffeine (Caf). Redrawn from data of references $[1,2]$.

plied, use of occlusive or nonocclusive conditions, time of wash or product removal). To realize this goal a new diffusion cell system was created in which the epidermis is left open to ambient laboratory conditions and the dermis is bathed by a suitable receptor solution, usually buffered isotonic saline, maintained at $37^{\circ} \mathrm{C}$. Thus, the in vivo state in which both a temperature and water gradient exist across the skin is replicated; the epidermal surface is readily accessible for dose application, dose removal, and/or surface wash.

In an attempt to validate the model, a study was conducted in which the absorption of twelve organic compounds was measured and the data compared with those obtained in living man years earlier by Feldmann and Maibach [2]. A comparison of the two data sets is presented in figure 1. For 8 of the 12 compounds in vitro:in vivo (IVIV) correlation was reasonably good, but for the other four compounds 4 - to 10 -fold differences in total absorption were encountered.

Since this was a retrospective comparison of the in vitro model to living man, not all of the critical variables could be controlled (table 1) and it was hypothesized that lack of correlation for all compounds might be due to differences in the protocols rather than a failure of the model. To test this hypothesis, a follow-up study was conduct- ed in which new in vitro and in vivo data were obtained on the four questionable compounds, and in which the IVIV protocol differences of the first studies were now harmonized [3]. Both sets of experiments were conducted on abdominal skin using radiolabeled compounds, the application sites were protected with a nonocclusive covering, and a skin wash was performed at $24 \mathrm{~h}$. In addition, collection of urine in vivo was not limited to 5 days, as was the case in the prior study, but extended until background levels of radioactivity were approached. This was done because several compounds in the original in vivo study showed high levels of radioactivity in the 5th day's collection, suggesting incomplete systemic clearance. Thus, whereas the in vitro study duration of 2 days was sufficient to characterize the absorption of the compounds into and through the skin, the in vivo study required extended urine collections to accommodate systemic distribution, metabolism, and excretion. The results are presented in table 2.

Excellent agreement was noted between the two sets of data and some of the reasons for the discrepancies in the original IVIV comparison became apparent. Longer urinary collection times were needed for thiourea and nicotinic acid and, in addition, it was discovered that an incorrect urinary correction factor had been used for nicotinic acid in the original Feldmann and Maibach study [see ref. 3]. Regional variation (forearm vs. abdomen) may have accounted for some of the differences noted in the earlier study, but it was also found that caffeine absorption was much greater in the second in vitro study than the first even though the site was the same. As intersubject variability can be large, and only small numbers of donor skins were utilized, this may also have been a contributing factor.

Two additional IVIV correlation studies were subsequently conducted to add to the body of data supporting use of excised human skin as a valid surrogate for living man: a study to examine the effect of vehicle on absorption [4], and a study of benzene absorption in man [5].

Good IVIV correlation was again seen (table 3). The caffeine water gel turned out to be of particular interest, because this was a vehicle with low caffeine bioavailability, and it served to confirm the sensitivity of the model at distinguishing between vehicles. Likewise, the measurement of benzene absorption demonstrated the ability of the model to quantify permeation of a volatile compound from an un-occluded finite dose, which also closely matched the in vivo results.

Collation of data from the four studies cited above demonstrates that, for the twenty comparisons of differ- 
Table 1. Comparison of in vitro versus in vivo protocols, original versus harmonized

\begin{tabular}{lllll}
\hline & $\begin{array}{l}\text { In vitro } \\
\text { Franz [1] }\end{array}$ & $\begin{array}{l}\text { In vivo } \\
\text { Feldmann and Maibach [2] }\end{array}$ & $\begin{array}{l}\text { Revised in vitro } \\
\text { Franz [3] }\end{array}$ & $\begin{array}{l}\text { Revised in vivo } \\
\text { Franz [3] }\end{array}$ \\
\hline Site & abdomen & forearm & abdomen & abdomen \\
Vehicle & acetone & acetone & acetone & acetone \\
Dose & $4-40 \mu \mathrm{g} / \mathrm{cm}^{2}$ & $4 \mu \mathrm{g} / \mathrm{cm}^{2}$ & $4 \mu \mathrm{g} / \mathrm{cm}^{2}$ & $4 \mu \mathrm{g} / \mathrm{cm}^{2}$ \\
Protect site & yes & no & yes & yes \\
Skin wash & no & $24 \mathrm{~h}^{*}$ & $24 \mathrm{~h}$ & $24 \mathrm{~h}$ \\
Collection time & 2 days & 5 days & 2 days & $7-21$ days \\
\hline
\end{tabular}

* Subjects prohibited from washing for $24 \mathrm{~h}$, but wash time otherwise unspecified. Numbers in brackets are references from which the methods were taken.

ent compounds and vehicles examined in the excised human skin model, correlation with data from living man was excellent (fig. 2). The overall mean IVIV ratio was 1.25. Not only does this data demonstrate the validity of the in vitro model, it also points out the importance of a harmonized protocol design.

\section{In vitro:in vivo Correlation: Transdermal Delivery}

Strong support for the relevance of the excised human skin model can also be found in the field of transdermal drug delivery where measurement of percutaneous absorption is a critical step in early development. If one assumes that the steady state flux through skin in vitro is equivalent to the rate of input to the systemic circulation in vivo (analogous to a continuous intravenous infusion), then the model can be used to assess the progress of formulation development prior to clinical evaluation according to the following equation [6]:

$$
\mathrm{J}_{\mathrm{ss}} \times \mathrm{A}=\mathrm{C}_{\mathrm{ss}} \times \mathrm{Cl}_{\mathrm{s}}
$$

where $\mathrm{J}_{\mathrm{ss}}=$ steady-state flux through skin, $\mathrm{A}=$ area of skin, $\mathrm{C}_{\mathrm{ss}}=$ steady-state blood concentration, $\mathrm{Cl}_{\mathrm{s}}=$ systemic clearance.

Since the development of transdermal dosage forms generally occurs subsequent to the development of other dosage forms for a given drug, the therapeutic blood level $\left(\mathrm{C}_{\mathrm{ss}}\right)$ and systemic clearance $\left(\mathrm{Cl}_{\mathrm{s}}\right)$ are already known, and calculation of the target transdermal flux is straightforward.

The utility of this approach was initially shown by the Alza Corporation during the development of the first transdermal product, Transderm-Scop ${ }^{\circledR}$, and led them to conclude that '.. in vitro accurately predicted the situation which pertains in vivo' [7].
Table 2. Total absorption from IVIV study conducted under harmonized protocol

\begin{tabular}{lrrr}
\hline Compound & $\begin{array}{l}\text { In vitro* } \\
\text { (\% dose })\end{array}$ & \multicolumn{1}{l}{$\begin{array}{l}\text { In vivo* } \\
\text { (\% dose) }\end{array}$} & $\begin{array}{l}\text { Urine } \\
\text { (days) }\end{array}$ \\
\hline Hippuric acid & $1.25 \pm 0.25(4)$ & $1.0 \pm 0.16(6)$ & 3 \\
Nicotinic acid & $2.3 \pm 0.45(4)$ & $2.1 \pm 0.40(3)$ & 21 \\
Thiourea & $4.6 \pm 1.03(5)$ & $3.7 \pm 0.65(4)$ & 21 \\
Caffeine & $24.1 \pm 3.90(4)$ & $22.1 \pm 7.90(4)$ & 7 \\
\hline
\end{tabular}

* Mean \pm SE (number of subjects or skin donors). Data from Franz [3].

Table 3. Total absorption from two IVIV studies conducted under a harmonized protocol

\begin{tabular}{llll}
\hline Compound & Vehicle & $\begin{array}{l}\text { In vitro* } \\
\text { (\% of dose) }\end{array}$ & $\begin{array}{l}\text { In vivo* } \\
\text { (\% of dose) }\end{array}$ \\
\hline Testosterone & petrolatum & $39.4 \pm 1.2(20)$ & $49.5 \pm 5.8(3)$ \\
& EG gel & $23.7 \pm 2.0(5)$ & $36.3 \pm 0.4(4)$ \\
Caffeine & water gel & $41.4 \pm 6.8(8)$ & $49.2 \pm 4.7(4)$ \\
& petrolatum & $40.6 \pm 2.2(7)$ & $40.6 \pm 6.1(5)$ \\
& EG gel & $32.2 \pm 7.3(6)$ & $55.6 \pm 11.7(4)$ \\
Benzoic acid & water gel & $5.1 \pm 0.5(7)$ & $4.0 \pm 0.5(4)$ \\
Benzene & betrolatum & $46.5 \pm 5.9(6)$ & $60.6 \pm 10.7(4)$ \\
\hline
\end{tabular}

* Mean \pm SE (number of subjects or skin donors). Data from $[4,5]$.

Other studies involving transdermal products also illustrate the validity of the model. Both Hadgraft et al. [8] and Rohr et al. [9] found excellent correlation between data obtained in vitro with that of living man for nitroglycerin and estradiol, respectively. Especially informa- 


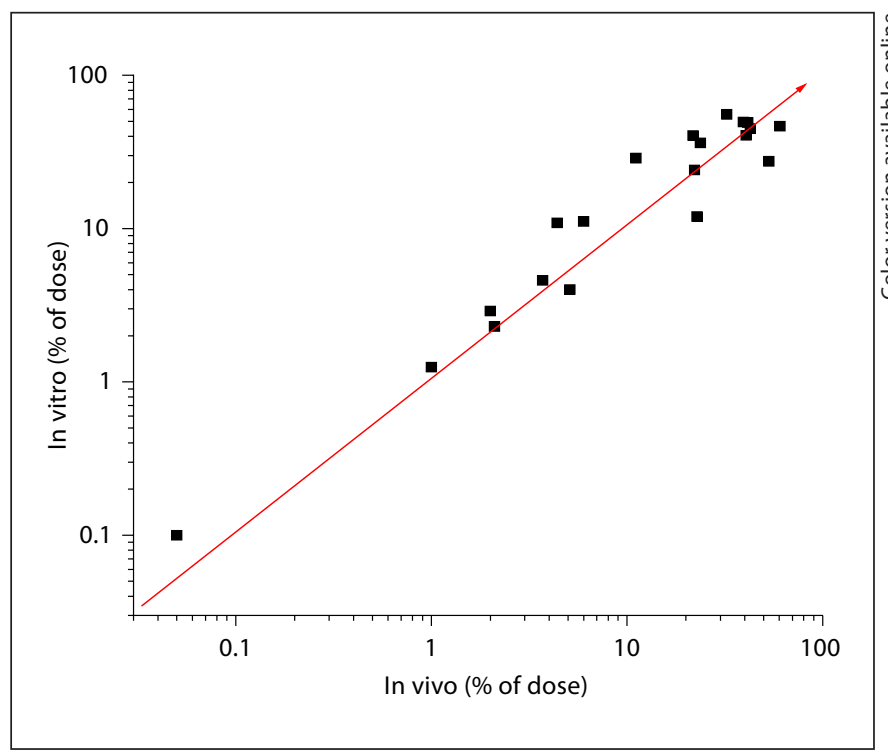

Fig. 2. IVIV comparison of total absorption (\% of applied dose) for twenty compound/vehicle combinations. Line represents theoretical one-to-one correlation. The in vitro:in vivo ratios ranged from $0.52-2.59$ with an overall mean of 1.25. Data from references [1-5].

tive, due to the unusually large amount of data generated, is the work reported by Venkateschwaran on the development by TheraTech Inc. of transdermal testosterone (Androderm $^{\circledR}$ ) and estradiol (Alora ${ }^{\circledR}$ ) [10]. When expressed as average cumulative absorption, the rate of absorption profiles obtained in vitro for both drugs were strikingly similar to those obtained in vivo (fig. 3). Although the data for estradiol showed divergence in absorption after $48 \mathrm{~h}$, this difference was readily explainable by the conditions of the experiment in which the area available for diffusion in vitro was only $67 \%$ of the total patch area. This led to a lower rate of drug depletion from the patch in vitro than in vivo since part of the patch was not in contact with the skin.

\section{Utility for Bioequivalence}

When all of these examples are taken together it is apparent that a significant body of data exists in both the topical and transdermal drug fields to support the proposition that the use of excised human skin is a valid model by which to assess the bioavailability of various drugs and other chemicals which come in contact with the skin. The objective of the present work is to evaluate the utility of the model in the field of bioequivalence. Is the model sufficiently discriminating and does it have the requisite

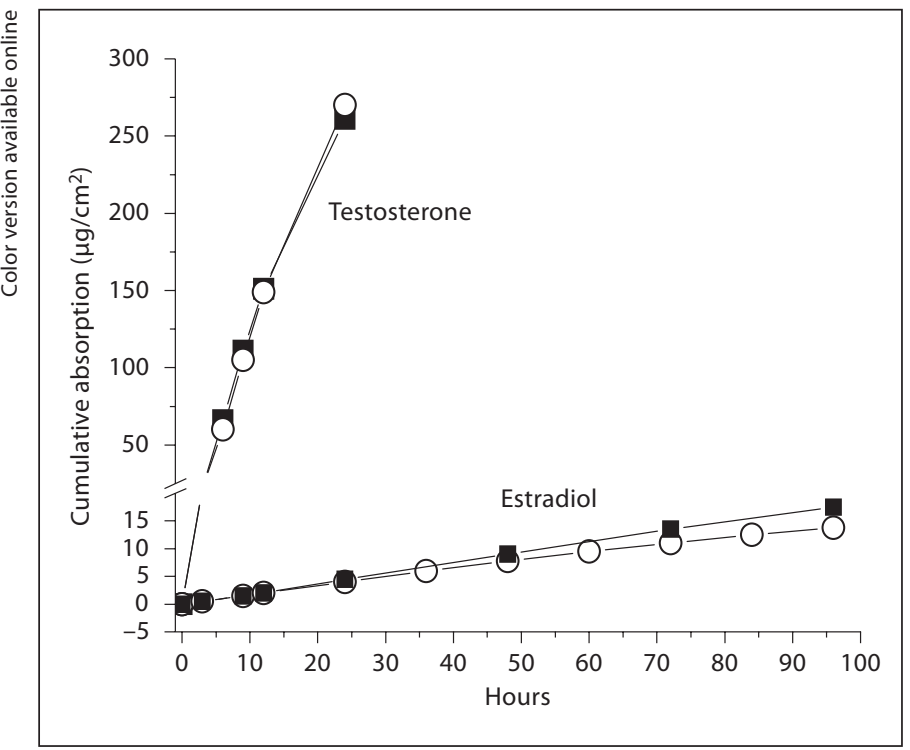

Fig. 3. Comparison of the rate of absorption of estradiol and testosterone from separate transdermal systems as measured in vitro $(\boldsymbol{\square})$ in excised skin and in vivo $(O)$ in human subjects. The in vivo rate was determined by measuring drug loss from the patch. Redrawn from data of reference [10].

statistical power to justify its acceptance by regulatory agencies as a surrogate for clinical testing?

To address these issues concerning the validity of the excised human skin model, a study was conducted to evaluate its suitability as a surrogate for clinical bioequivalence testing. Specifically, the in vitro pharmacokinetics of seven generic topical drug products was characterized and compared with their corresponding reference products during preclinical development. Thereafter, following the regulatory approval of these generic products in the United States, clinical data from their bioequivalence trials became available to which the in vitro data could be compared. Of note, in five of the seven comparisons the same lots of both test and reference products used in vivo had been used in vitro.

\section{Materials and Methods}

\section{Materials}

Generic versions of the following products were studied and compared to the reference listed drugs (RLD): tretinoin (Retin$\mathrm{A}^{\circledR} 0.01 \%$ and $0.025 \%$ gel), alclometasone dipropionate (Aclovate ${ }^{\circledR}$ $0.05 \%$ cream and ointment), halobetasol propionate (Ultravate ${ }^{\circledR}$ $0.05 \%$ cream and ointment), and mometasone furoate (Elocon ${ }^{\circledR}$ $0.1 \%$ ointment). All generic and reference products were provided by the sponsors. 
For the in vitro absorption studies with the tretinoin formulations, radioactive drug $\left(20\right.$-methyl- ${ }^{3} \mathrm{H}$-all trans retinoic acid, specific activity $73.6 \mathrm{Ci} / \mathrm{mmol}, 4.0 \mathrm{mCi} / \mathrm{ml}$ in ethanol; New England Nuclear Corporation, Boston, Mass., USA) was added to both the generic and RLD formulations, mixed and allowed to equilibrate at room temperature a minimum of two days to allow for further diffusional mixing before the first experiment was initiated. All procedures were conducted under yellow light to prevent photodegradation of the drug. Spiking with the ${ }^{3} \mathrm{H}$-tretinoin led to an immeasurable increase in drug content (approximately $1 \mathrm{ng}$ 'hot' per $1,250 \mathrm{ng}$ 'cold' for the $0.01 \%$ strength), and no more than a $0.5 \%$ change in vehicle content ( $1 \mathrm{mg}$ ethanol per $200 \mathrm{mg}$ gel)

Other materials used in the in vitro studies included ${ }^{3} \mathrm{H}_{2} \mathrm{O}$ (New England Nuclear Corporation), which was diluted in distilled-deionized water to make a stock solution $\sim 0.5 \mu \mathrm{Ci} / \mathrm{ml}$, Volpo-20 (Oleth-20, CAS No. 9004-98-2, Croda Inc., Parsippany, N.J., USA), and Opti-Fluor scintillation fluid (Packard Instruments Company, Downers Grove, Ill., USA).

\section{In vitro Absorption}

Skin Preparation and Integrity

Percutaneous absorption was measured using the finite dose technique [3]. Cryopreserved, dermatomed (0.5-0.9 $\mathrm{mm}$ ) human cadaver trunk skin was obtained from a skin bank and stored in water-impermeable plastic bags at $-70^{\circ} \mathrm{C}$ until used; generally within ten months of the donor's death, although the specimens are certified to be viable for a period of 5 years.

Prior to the experiment, skin was removed from the bag, placed in $\sim 37^{\circ} \mathrm{C}$ water until thawed, and then cut into sections large enough to fit on $0.8 \mathrm{~cm}^{2}$ Franz Cells. The dermal chamber was filled with phosphate-buffered isotonic saline (PBS), pH 7.4 \pm 0.1 , and the epidermal chamber (chimney) left open to ambient laboratory conditions. All cells were mounted in a diffusion apparatus in which the dermal bathing solution was stirred magnetically at approximately $600 \mathrm{rpm}$ and its temperature controlled to maintain skin surface temperature at $32 \pm 0.5^{\circ} \mathrm{C}$ [11].

To assure barrier integrity of each skin section, its permeability to tritiated water was determined before application of the test products [12]. Following a brief $(0.5-1 \mathrm{~h})$ equilibrium period, ${ }^{3} \mathrm{H}_{2} \mathrm{O}$ was layered across the top of the skin by dropper so that the entire exposed surface was covered (approximately 100-150 $\mu \mathrm{l}$ ). After 5 min the ${ }^{3} \mathrm{H}_{2} \mathrm{O}$ aqueous layer was removed and the skin surface blotted dry. At $30 \mathrm{~min}$ after application the receptor solution was collected and analyzed for radioactive content by liquid scintillation spectrometry. Skin specimens in which absorption of ${ }^{3} \mathrm{H}_{2} \mathrm{O}$ was less than $1.25 \mu$ l-equ were considered acceptable. Sections failing this criterion were either discarded or used as non-dosed, blank analytical control chambers.

\section{Percutaneous Absorption}

Following the barrier integrity test the receptor solution was changed in accord with the needs of the drug under study: (a) tretinoin: pH 7.4 PBS + 0.5\% Volpo-20, (a nonionic surfactant used in the reservoir solution to increase solubility of poorly water soluble compounds and to ensure sink conditions [13]), or (b) glucocorticoids: pH 7.4 1:10 PBS. Prior to dosing with the test product, the chimney was removed from the cell to allow full access to the epidermal surface of the skin. All formulations were applied using a positive displacement pipette set to deliver $5 \mu \mathrm{l}$ and the dose spread over the entire exposed surface with the Teflon tip of the pipette. 5-10 min after application the chimney portion of the cell was replaced.

At preselected time intervals, the receptor solution was removed in its entirety and replaced with fresh solution to maintain sink conditions and an aliquot was taken for subsequent analysis. The data were used to calculate both a rate of absorption for each time period and total absorption for the entire 48-hour period of the study. During the tretinoin studies, the lab was maintained in total darkness or dim yellow light to duplicate the customary dosing recommendations (apply nightly before retiring) and to minimize photodegradation of the drug.

All product comparisons were conducted side-by-side on skin sections from the same donors. Three replicate sections from each of 3 donors $(n=9)$ were used per product in the glucocorticoid studies, and 3-4 replicate sections from each of 7 donors $(n=27$, $0.025 \%$ gel) or 8 donors $(n=31,0.01 \%$ gel) in the tretinoin studies. The different sample sizes were determined by the different objectives of the studies. The glucocorticoid studies were conducted as a screening tool to select, from multiple lots of generic and RLD product, the two that most closely matched and, therefore, the two most likely to be proven bioequivalent in the pivotal clinical trial. The tretinoin studies were designed to emulate a bioequivalence trial and a greater number of donor skins were used to satisfy the more rigorous statistical requirements of a pivotal trial.

Analytical Methods

All tretinoin samples were assayed by liquid scintillation spectrometry. One milliliter of receptor solution was mixed with 5.0 $\mathrm{ml}$ Opti-Fluor scintillation fluid and assayed for radioactive content using a Perkin-Elmer Tri-Carb Model 3100TR scintillation spectrometer. Each sample was counted for a minimum of $5 \mathrm{~min}$, in duplicate. Counts per min (cpm) were automatically converted to disintegration per min (DPM) using the external standard quench correction method.

All five glucocorticoid drugs required concentration of the receptor solution prior to analysis due to the small amounts absorbed. A 4-ml aliquot of receptor solution was taken and vacuum dried (Savant SpeedVac, Farmingdale, N.Y., USA), then redissolved in $0.1 \mathrm{ml}$ high-performance liquid chromatography (HPLC) solvent with vortexing and sonication.

HPLC was performed on a Hewlett-Packard 1090 Series HPLC system with both UV diode array and atmospheric pressure ionization - electrospray (API-ES) mass spectrometer detectors. All methods utilized a C18 Luna $^{\mathrm{TM}}$ column $(4.6 \times 100 \mathrm{~mm}, 3 \mu \mathrm{m}$, Phenominex, Inc.) at a solvent flow rate of $0.5 \mathrm{ml} / \mathrm{min} .20 \mu \mathrm{l}$ of sample was injected. Peak areas were quantified to concentration using an external standard curve prepared from neat standard. Differences in the HPLC method between the glucocorticoids were in the eluting solvent used. Specifically, for halobetasol propionate the solvent consisted of $60 \%$ acetonitrile, $40 \%$ water, and $0.1 \%$ formic acid; for alclometasone dipropionate and mometasone furoate the solvent consisted of $65 \%$ acetonitrile, $35 \%$ water, and $0.1 \%$ formic acid.

\section{Data Analysis and Statistics}

The rate of absorption $\left(\mathrm{ng} / \mathrm{cm}^{2} / \mathrm{h}\right)$ was determined by dividing the amount absorbed in a given sampling interval by the length of that interval in hours and adjusting for dosed area. The mean at each sampling time was calculated by averaging the data from all skin sections per formulation (glucocorticoids $n=9,0.01 \%$ 
Table 4. IVIV comparison of five generic glucocorticoid products (test) versus the corresponding reference products

\begin{tabular}{|c|c|c|c|c|c|c|}
\hline & \multicolumn{3}{|c|}{ In vitro absorption ${ }^{\mathrm{a}}, \mathrm{ng} / \mathrm{cm}^{2} / 48 \mathrm{~h}$} & \multicolumn{3}{|c|}{ In vivo $\mathrm{VC}$ assay ${ }^{\mathrm{a}}$, negative $\mathrm{AUEC}_{0-24 \mathrm{~h}}$} \\
\hline & test & reference & test/reference & test & reference & test/reference \\
\hline Alclometasone cream & 4.52 & 4.39 & 1.03 & 18.5 & 16.8 & 1.10 \\
\hline Alclometasone ointment & 66.95 & 70.0 & 0.96 & 16.0 & 17.4 & 0.92 \\
\hline Halobetasol cream & 110.4 & $96.9^{\mathrm{b}}$ & 1.14 & 33.1 & 30.7 & 1.08 \\
\hline Halobetasol ointment & 246.7 & 256.3 & 0.96 & 28.6 & 28.5 & 1.00 \\
\hline Mometasone ointment & 213.4 & 338.7 & 0.63 & 13.7 & 12.3 & 1.11 \\
\hline
\end{tabular}

${ }^{a}$ Listed numbers are mean values.

b Average of 3 reference lots, none of which were used in the VC study. In all other comparisons identical lots of test and reference products were used in both the in vivo and the in vitro studies.

tretinoin $\mathrm{n}=31,0.025 \%$ tretinoin $\mathrm{n}=27$ ) and the data are presented graphically without further analysis.

Total absorption $\left(\mathrm{ng} / \mathrm{cm}^{2} / 48 \mathrm{~h}\right)$ into the dermal receptor solution was calculated from the sum of the drug content found in all receptor samples $(0 \rightarrow 48 \mathrm{~h}$ ) adjusted for dose area. Mean total absorption $( \pm$ SEM) was calculated by averaging across all skin sections for each formulation. Statistical analysis of the data was conducted using the Student's t test as well as two-way analysis of variance (ANOVA), with additional post-hoc means comparisons using Bonferroni and Tukey tests.

In the case of tretinoin statistical analysis was based on natural log-transformed data. The estimated error standard deviation was used to compute the $90 \%$ confidence intervals for the ratios of the means (Test/Ref) of the listed parameters.

\section{Results}

\section{Glucocorticoids}

A comparison of the results obtained in vitro with those obtained in vivo is presented in table 4 . The in vivo data were provided by the sponsor of the clinical trials. All five-test steroids had been shown to be bioequivalent to the corresponding RLD by vasoconstrictor (VC) assay conducted according to FDA Guidance [14]. The demonstration of bioequivalence was based on statistical analysis showing that the $90 \%$ confidence interval on the test:reference ratio was within 0.80-1.25.

Data indicating equivalence of test and reference products was also obtained in the in vitro permeation model for 4 of the 5 glucocorticoids, where the test:reference ratio approximated unity and no statistically significant differences were identified by Student's $t$ test or ANOVA. Only the mometasone furoate ointment formulation failed to demonstrate a test:reference ratio close to one, despite the fact that there was no significant difference between test and reference. However, the lack of statistical significance was likely a result of the small number of skin sections evaluated $(n=9)$.

The in vitro determinations of equivalence that are evident based upon total absorption alone are further supported by examination of the rates of absorption (fig. 4). The striking similarity of the rate profiles for each pair of steroid products further serve to demonstrate the capability of the in vitro model for bioequivalence testing.

\section{Tretinoin}

Two AB-rated (therapeutically equivalent) generic tretinoin gels, $0.01 \%$ and $0.025 \%$ (Spear Pharmaceuticals), were compared to the RLD (Retin- $A^{\circledR}$ Gel, Johnson \& Johnson) in the in vitro skin model. Analogous to the procedure used in oral bioequivalence studies, test and reference products were compared with respect to three primary endpoints: total absorption (AUC, $\mathrm{ng} / \mathrm{cm}^{2}$ ), maximum rate of absorption $\left(\mathrm{J}_{\max }, \mathrm{ng} / \mathrm{cm}^{2} / \mathrm{h}\right)$, and time of maximum rate of absorption $\left(\mathrm{T}_{\max }, \mathrm{h}\right)$. In agreement with the clinical efficacy data upon which regulatory approval was based, equivalence was also found in the in vitro model (table 5). The confidence intervals for all three primary endpoints were within the interval 0.80 1.25 with $0.01 \%$ tretinoin and for two of three endpoints with $0.025 \%$ tretinoin. The third endpoint $\left(\mathrm{J}_{\max }\right)$ barely failed at 1.27.

The rate of absorption profiles for both sets of tretinoin products are presented in figure 5. Comparison of the two strengths with respect to both total absorption and maximum rate of absorption reveal an increase in magnitude proportionate to the 2.5 -fold increase in drug 

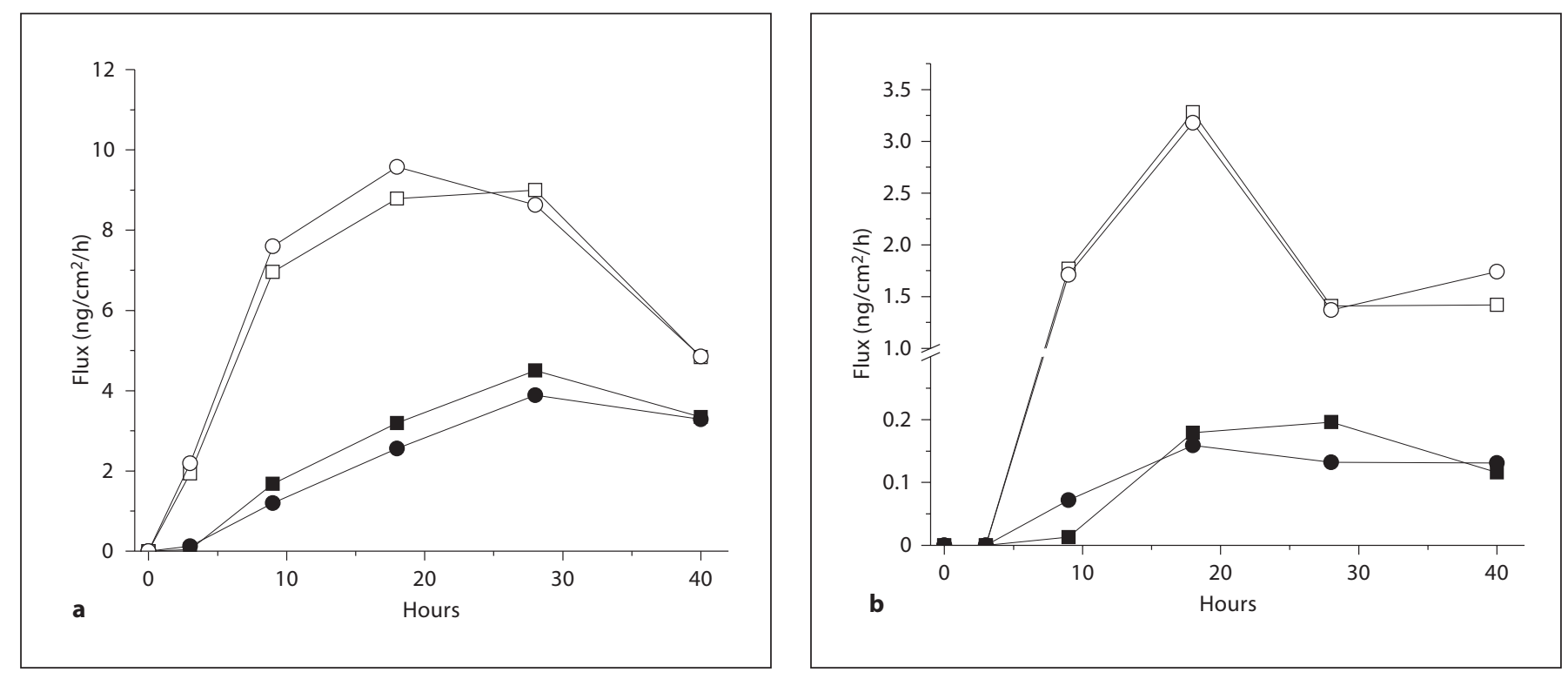

Fig. 4. In vitro percutaneous absorption of (a) Halobetasol propionate, and (b) alclometasone dipropionate. $\mathbf{\square}=$ Test cream, $\boldsymbol{\bullet}=$ reference cream; $\square$ = test ointment, $\bigcirc=$ reference ointment.

Table 5. In vitro comparison of the primary endpoints for test and reference tretinoin gels

\begin{tabular}{|c|c|c|c|c|}
\hline & Test & Reference & $\begin{array}{l}\text { Test/ref- } \\
\text { erence }\end{array}$ & $90 \% \mathrm{CI}^{\mathrm{a}}$ \\
\hline \multicolumn{5}{|c|}{$0.01 \%$ tretinoin gel } \\
\hline AUC & 3.00 & 2.97 & 1.02 & $97.06-107.46$ \\
\hline $\mathrm{J}_{\max }$ & 0.55 & 0.57 & 1.04 & $92.53-115.05$ \\
\hline $\mathrm{T}_{\max }$ & 3.60 & 3.57 & 1.04 & $92.23-116.37$ \\
\hline \multicolumn{5}{|c|}{$0.025 \%$ tretinoin gel ${ }^{\mathrm{b}}$} \\
\hline AUC & 3.49 & 3.47 & 1.03 & $95.14-110.45$ \\
\hline $\mathrm{J}_{\max }$ & 0.91 & 0.88 & 1.11 & $95.08-127.88$ \\
\hline $\mathrm{T}_{\max }$ & 3.66 & 3.72 & 0.98 & $97.26-99.52$ \\
\hline
\end{tabular}

a $90 \%$ CIs for the ratios of the means (test/reference) of the listed parameters.

${ }^{b}$ Lots of test and reference material used were identical to those used in the clinical study.

concentration. The increase in maximum flux ranged from 2.2 to 2.6 for both the test and reference product pairs, and these differences between the 0.01 and $0.025 \%$ strengths were found to be highly significant by Student's $t$ test $(p<0.01)$. Thus, the in vitro model was capable of not only demonstrating the equivalence of similar dosage forms but also of demonstrating the nonequivalence of dissimilar dosage forms.

\section{Discussion}

Establishing the bioequivalence of topical drugs in the United States is not a simple process since, in contrast to oral medications, clinical efficacy trials are required for many of these products. Although the Food, Drug and Cosmetic Act and implementing regulations allow for utilization of other in vitro and in vivo methods, to date, only the vasoconstrictor assay for topical glucocorticoids has been approved as a surrogate method [14].

Other promising methods for demonstrating the bioequivalence of topical products are available [15]. Two, in particular, have been given consideration by the FDA as potentially suitable surrogates for clinical tests: (1) an in vivo dermatopharmacokinetic (DPK) method in which drug levels in the stratum corneum are assessed through the use of tape-stripping, and (2) an in vitro DPK method in which the rate and extent of permeation through ex vivo human skin is measured.

The first method was based on the fact that the stratum corneum is the compartment through which drugs must pass to move from the skin surface to their site of action in the deeper layers of the skin. Therefore, analysis of the kinetics of drug entry and exit from this compartment could be used to assess bioequivalence, a situation analogous to the use of the blood stream to assess the bioequivalence of oral drugs. A draft guidance on the meth- 

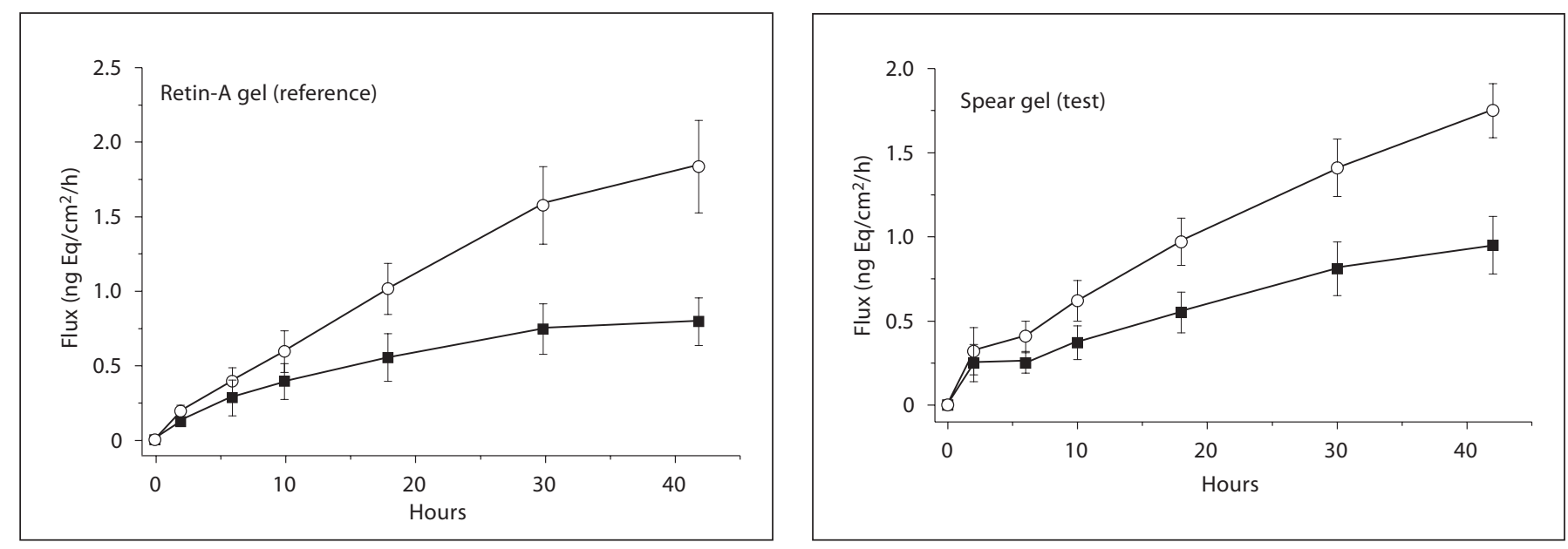

Fig. 5. Rate of absorption of tretinoin from both the $0.01 \%(\boldsymbol{\square})$ and $0.025 \%(\bigcirc)$ test and reference gels. Error bars represent $\pm \mathrm{SE}$.

od was issued by the FDA in 1998, but later withdrawn when a validation study conducted at two independent laboratories produced contradictory results [16-18]. Newer work, however, has further characterized the method and should stimulate regulatory re-evaluation, particularly for topical antifungal drugs in which the site of action is the stratum corneum itself [19].

An in vitro DPK method using human skin was actually considered by FDA much earlier than the in vivo DPK method [11]. However, the lack of a sufficient body of compelling data at that time stopped further consideration, a situation that has now changed. New data presented in this report offer substantial evidence to support the belief that the in vitro assessment of pharmacokinetics in excised human skin is a viable alternative to clinical testing.

\section{In vitro versus in vivo Results}

Seven generic drug products were evaluated during their preclinical development and active pharmaceutical ingredient (API) absorption from both test and reference products compared side-by-side in the excised skin model. The test products were later evaluated by clinical trial or VC assay where they were each shown to be bioequivalent to the RLD and subsequently approved by the FDA based on the clinical outcome as well as chemistry and manufacturing considerations. The in vitro data were never submitted because they currently have no regulatory status in the US. However, in agreement with the clinical data, the in vitro bioavailability of the test products were found to closely approximate that of the refer- ence products in six of seven cases, with test:reference ratios ranging from 0.96 to 1.14 . The glucocorticoid product, mometasone furoate ointment, was the sole exception where the test:reference ratio was observed to be 0.63 .

The explanation for this single discrepancy between the in vitro and clinical data appears to be a result of the greater sensitivity of the in vitro method to detect differences between products, rather than a failure of the in vitro method. Evidence to support this conclusion can be seen in table 4 and figure 4 . Examination of the data sets for alclometasone dipropionate $0.05 \%$ cream versus ointment reveal a striking disparity between the clinical data and the in vitro data. Although either method can demonstrate equivalence of the test and reference products, the VC assay cannot distinguish between cream and ointment (both formulations give similar area under the effect curve results). In this study, they appear to be of approximately equal potency, in keeping with historical data in which both are classified as group VI in the potency ranking scale of Stoughton [20]. In spite of this, total API absorption was found to be 15 -fold greater from the ointment than the cream product. Though comparison of permeation data from the cream and ointment products is problematic because the data were not obtained from the same donors in head-to-head studies, the difference is so large as to be beyond question. The validity of the comparison is also borne out by results obtained from a single donor skin that, by chance, was common to both cream and ointment studies. For this one donor, there was a $>25$-fold difference. 
Table 6. Comparison of vasoconstrictor potency of betamethasone valerate foam and lotion by $\mathrm{VC}$ assay at eight dose durations (mean negative AUEC $\pm \mathrm{SE}$ )

\begin{tabular}{lll}
\hline Dose duration, $h$ & Foam & Lotion \\
\hline 0.25 & $23.7 \pm 4.4$ & $22.7 \pm 4.1$ \\
0.5 & $20.3 \pm 4.5$ & $21.6 \pm 4.5$ \\
0.75 & $25.4 \pm 3.9$ & $28.1 \pm 3.5$ \\
1.0 & $20.8 \pm 3.9$ & $28.2 \pm 3.9$ \\
1.5 & $22.8 \pm 4.2$ & $28.8 \pm 4.2$ \\
2.0 & $27.3 \pm 4.7$ & $30.8 \pm 4.7$ \\
4.0 & $27.0 \pm 5.1$ & $34.2 \pm 4.5$ \\
6.0 & $29.4 \pm 4.9$ & $32.0 \pm 3.8$ \\
\hline
\end{tabular}

An even more striking example of the superiority of the excised skin model over the VC assay comes from a previously published study involving a comparison of betamethasone valerate foam and lotion. By clinical trial the efficacy of the foam product was found to be $50 \%$ greater than the lotion in the treatment of scalp psoriasis, and this was supported by permeation data that demonstrated a 3-fold greater rate of absorption from the foam formulation [21]. In spite of this, as can be noted in table 6 , the $\mathrm{VC}$ assay was unable to demonstrate the greater potency of the foam product [22].

Although the in vitro glucocorticoid studies were conducted for screening purposes, i.e. to select the test and reference lots whose in vitro bioavailability most closely matched, they were not statistically powered to meet bioequivalence standards. Therefore, calculation of confidence intervals was not done. Nonetheless, as few as 3 donors with three replicates per donor for each formulation were sufficient to demonstrate similarity or dissimilarity between the test and reference lots. To allow for increased power for confidence interval determinations, it is only a matter of a modest increase in the number of donors and replicates tested.

In contrast, the design of the tretinoin studies was guided specifically by the need to match FDA bioequivalence standards, the intent being to use the data to seek a waiver for the lower strength tretinoin gel following approval of the higher strength gel on the basis of a clinical efficacy study. The results indicate that the in vitro model is capable of successfully achieving the rigorous statistical requirements of the FDA with a reasonable number of skin sections. The protocol required each product comparison to be run on skin from eight donors with four replicate determinations per product per donor $(\mathrm{n}=$ 8 donors:32 skin sections). Based on the tritiated water barrier integrity test, an unusually high rejection rate of skin sections from some donors was encountered and the final numbers fell below the target number $(0.01 \%$ gel $=$ $8: 31,0.025 \%$ gel $=7: 27)$. In spite of this the $90 \%$ confidence interval fell within the required interval $0.80-1.25$ for all three primary endpoints with $0.01 \%$ tretinoin gel and for two of three primary endpoints with $0.025 \%$ tretinoin gel, with the third endpoint $\left(\mathrm{J}_{\max }\right)$ being very close (1.27).

In addition to being able to demonstrate the bioequivalence of two products that are known to be bioequivalent, an important prerequisite for the establishment of any surrogate test is that it has the sensitivity to differentiate between two products that are known not to be bioequivalent. The tretinoin study presented a unique opportunity to probe this requirement since both tretinoin strengths were compared side-by-side on the same donor skins. The finding of statistically significant differences in total absorption and maximum rate of absorption between the 0.01 and $0.025 \%$ gels for both the test and reference products confirmed the sensitivity of the in vitro model. This is a critically important observation since there is not a more important test of the discriminatory capacity of any model than that of differentiating between changes in the concentration of the API itself.

\section{Methodological Issues}

Widespread use of the excised skin model by industry and academic scientists alike implies a high level of acceptance of its relevance and validity, yet doubts still persist regarding its general applicability as well as the accuracy and precision of the model. Given the lack of circulation, glandular secretion, and metabolic activity (in most cases), justifiable questions can be raised as to whether the model is always a perfect mimic of the in vivo state.

Apropos to the present work are the issues of skin preparation and receptor solution composition, due to the low water solubility of the test drugs studied. There is general recognition of the fact that the use of full-thickness skin and a simple isotonic saline receptor solution will result in erroneously low absorption values when dealing with highly water insoluble compounds. In this study dermatomed skin was used to reduce the thickness of aqueous dermal compartment and, in the case of tretinoin, $0.5 \%$ Volpo- 20 was added to the receptor solution to increase its solubility from $<0.1$ to $40 \mu \mathrm{g} / \mathrm{ml}$. However, the adequacy of this approach has not been critically evaluated. Some believe that preparations of isolated epidermis may be better than dermatomed skin at replicating the in vivo state, and there are data to suggest that the use 
of Volpo-20 may fall short with highly water insoluble compounds $[13,23,24]$.

Nevertheless, it is unlikely that either solubility or dermal thickness issues adversely affected the results of the present study. Although total absorption of alclometasone from the cream product approximated only $0.2 \%$ of the dose, this low value could not have been limited by the method employed as total absorption from the ointment product was $2.8 \%$ of the dose. The latter value is remarkably similar to that given in the Physicians' Desk Reference (PDR) for alclometasone absorption in vivo in normal subjects, $3 \%$ following an 8-hour application [25]. No in vivo data were given for the alclometasone cream product.

Likewise, none of the in vivo values given in the PDR for the other three steroids studied were sufficiently greater than those found in vitro as to raise concern over the adequacy of in vitro method. Halobetasol absorption in vitro ranged from $4.4-10 \%$ of the dose for the cream and ointment, respectively; and $<6 \%$ absorption was found in vivo for both products. Total absorption of mometasone was $4.3-6.8 \%$ of the dose in vitro and $0.7 \%$ of the dose in vivo after $8 \mathrm{~h}$ of contact. The lower value found in vivo may have been caused by the short contact time with the skin. It would appear that a distinction may have to be made between poorly water-soluble compounds, as used in this study, and highly water-insoluble compounds, as used in the studies cited above where differences between in vitro and in vivo results were noted.

\section{Conclusions}

Historically, the in vitro finite dose model using excised human skin has proven to be a remarkably accurate representation of living man for assessing topical pharmacokinetics. When IVIV studies utilize a harmonized protocol, results obtained in our laboratory demonstrate excellent concordance between in vitro and in vivo data. A comparison of the pharmacokinetics of seven approved generic topical drug products with the corresponding RLD has confirmed that the results obtained in the in vitro human skin model are in agreement with the clinical results that were the basis for the regulatory designation of therapeutically equivalent. In one instance the greater sensitivity of the in vitro method versus the pharmacodynamic clinical method (VC assay) was clearly evident. These new results, taken collectively with those previously published in both the topical and transdermal fields of research, present a consistent picture of a method in which absorption data can be obtained that accurately replicate the living state. We believe that a compelling argument can now be advanced to support use of the in vitro human skin model, when used in a good laboratory practices-based environment, as a surrogate for more expensive and time-consuming in vivo bioequivalence studies.

\section{References}

1 Franz TJ: Percutaneous absorption: on the relevance of in vitro data. J Invest Dermatol 1975;64:190-195.

2 Feldmann RJ, Maibach HI: Absorption of some organic compounds through the skin in man. J Invest Dermatol 1970;54:399-404.

3 Franz TJ: The finite dose technique as a valid in vitro model for the study of percutaneous absorption in man; in Simon GA, Paster A, Klingberg MA, Kaye M (eds): Skin: Drug Application and Evaluation of Environmental Hazards. Curr Probl Dermatol. Basel, Karger, 1978, pp 58-68.

4 Bronaugh RL, Franz TJ: Vehicle effect on percutaneous absorption: in vivo and in vitro comparisons. Br J Dermatol 1986;115:111.

5 Franz TJ: Percutaneous absorption of benzene. Adv in Mod Envir Toxicol 1984;6:6170.
6 Gibaldi M, Perrier D: Pharmacokinetics, ed 2. New York, Marcel Dekker, 1982, p 321.

7 Shaw JE, Chandrasekaran SK, Michaels AS, Taskovich L: Controlled transdermal delivery, in vitro and in vivo; in Maibach HI (ed): Animal Models in Dermatology, New York, Churchill-Livingstone, 1975, pp 138-146.

8 Hadgraft J, Beutner D, Wolff H: In vivo-in vitro comparisons in the transdermal delivery of nitroglycerin. Int J Pharm 1993;89: R1-R4.

9 Rohr UD, Altenburger R, Kissel T: Pharmacokinetics of the transdermal reservoir membrane system delivering $\beta$-estradiol: in vitro/in vivo-correlation. Pharm Res 1998; 15:877-882.

10 Venkateshwaran S: In vitro-in vivo correlation for transdermal delivery. IBC International Conference on Transdermal Drug Delivery, Coronado, 1997, pp 15-16.
$>11$ Skelly JP, Shah VP, Maibach HI, Guy RH, Wester RC, Flynn G, Yacobi A: FDA and AAPS report of the workshop on principles and practices of in vitro percutaneous penetration studies: relevance to bioavailability and bioequivalence. Pharm Res 1987;4:265267.

12 Franz TJ, Lehman PA: The use of water permeability as a means of validation of skin integrity in in vitro percutaneous absorption studies. J Invest Dermatol 1990;94:525.

13 Bronaugh RL, Stewart RF: Methods for in vitro percutaneous absorption studies III. Hydrophobic compounds. J Pharm Sci 1984;73: 1255-1258.

14 Guidance for Industry: Topical Dermatologic Corticosteroids: In vivo Bioequivalence. Rockville, Center for Drug Evaluation and Research, Food and Drug Administration, 1995. www.fda.gov/cder/guidance/old098fn. pdf 
-15 Herkenne C, Alberti I, Naik A, Kalia YN, Mathy F, Preat V, Guy RH: In vivo methods for the assessment of topical drug bioavailability. Pharm Res 2008;25:87-103.

16 FDA, CDER: Guidance: topical dermatological drug product NDAs and ANDAs-in vivo bioavailability, bioequivalence, in vitro release, and associated studies. Draft guidance, June 1998. www.fda.gov/ohrms/ dockets/ac/00/backgrd/3661blc.pdf.

17 Pershing LK: Bioequivalence assessment of three $0.025 \%$ tretinoin gel products: dermatopharmacokinetic vs. clinical trial methods, transcribed presentation to the Advisory Committee for Pharmaceutical Sciences Meeting, Center for Drug Evaluation and Research (CDER). Rockville, Food and Drug Administration, 2001. Presentation slides available at http://www.fda.gov/ohrms/ dockets/ac/01/slides/3804s2_02_Pershing/ index.htm; transcript available at http:// www.fda.gov/ohrms/dockets/ac/01/ transcripts/3804t2_01_Morning_Session. pdf pp 31-47.
18 Franz TJ: Study \#1, Avita Gel 0.025\% vs. Retin-A Gel 0.025\%: transcribed presentation to the Advisory Committee for Pharmaceutical Sciences Meeting, Center for Drug Evaluation and Research (CDER). Rockville, Food and Drug Administration, 2001. Presentation slides available at http://www.fda. gov/ohrms/dockets/ac/01/slides/3804s2 03_franz.pdf; transcript available at http:// www.fda.gov/ohrms/dockets/ac/01/ transcripts/3804t2_01_Morning_Session. pdf pp 47-61.

19 N'Dri-Stempfer B, Navidi WC, Guy RH, Bunge AL: Improved bioequivalence assessment of topical dermatological drug products using dermatopharmacokinetics. Pharm Res 2009;26:316-328.

20 Stoughton RB: Vasoconstrictor assay: specific applications; in Maibach HI, Surber C (eds): Topical Corticosteroids. Basel, Karger, 1992, pp 42-53.
21 Franz TJ, Parsell DA, Halualani RM, Hannigan JF, Kalbach JP, Harkonen WS: Betamethasone valerate foam $0.12 \%$ : a novel vehicle with enhanced delivery and efficacy. Int J Dermatol 1999;38:628-632.

22 FDA, CDER: Summary Basis of Approval: NDA 20-934, Luxiq (betamethasone valerate) foam. Clin Pharmacol Biopharm Rev 1999:28 Feb. www.fda.gov/cder/foi/nda/99/ 20934.htm.

23 Scott RC, Ramsey JD: Comparison of the in vivo and in vitro percutaneous absorption of a lipophilic molecule (cypermethrin, a pyrethroid insecticide). J Invest Dermatol 1987; 89:142-146

24 Ramsey JD, Woollen BH, Auton TR, Scott $\mathrm{RC}$ : The predictive accuracy of in vitro measurements for the dermal absorption of a lipophilic penetrant (fluazifop-butyl) through rat and human skin. Fund Appl Toxicol 1994; 23:230-236.

25 Physicians' Desk Reference, ed 58. Montvale, Thomson PDR, 2004. 